\title{
An integrated model for mechatronic products in agile manufacturing system
}

\author{
Seyed Mohammad Seyedhosseini and Amirreza Keyghobadi*
}

Department of Industrial Management, Science and Research Branch, Islamic Azad University, Tehran, Iran

\section{CHR ON I C LE AB S T RAC T}

Article history:

Received February 14, 2014

Accepted May 29, 2014

Available online

May 312014

Keywords:

Mechatronics

Integrated Model

Products Design and Development

Agile Manufacturing

Competitive Environment

\begin{abstract}
Reviewing the evolutionary trend of the models used in design and development of mechatronic products reveals the necessity for integration of the design characteristics and requirements in various engineering fields. Such products should agilely embrace rapid, persistent and complex requirements in competitive environments. This research aims to develop an integrated model for designing and developing mechatronic products within the context of agile production system. The study tries to eliminate unnecessary stages of design and simulation of products and increase the number of tested ideas. This suggests a distinction between product innovation and product improvement cycles and thus makes employing a pre-active approach to responding possible. Since the term "mechatronic products" is often used interchangeably with "robots", one of the most commonly used types of them, i.e. tracer robot is considered as the statistical population for the proposed study. By choosing experimental (laboratory) research method, two categories of tracer robots are created: the tracer robots based on the V-model as the only integrated existing model and the robots based on the $\mathrm{W}$-model as the model proposed by this study with a sample size of 35 sets in each group. The results indicate that both method provide acceptable validity although one model seems to perform better than the other one.
\end{abstract}

(C) 2014 Growing Science Ltd. All rights reserved.

\section{Introduction}

The competitive market and the rapid, continuous, and complex consumer demands have led to great innovation in production and manufacturing, from mass production to lean and agile manufacturing. Agile manufacturing involves capitalizing on people, advanced information, and production technologies to realize rapid and effective responses to unexpected market changes. In addition, these changes in manufacturing have been accompanied by a transition in development methods, from single-discipline to multidisciplinary, interdisciplinary, and supra-disciplinary fields. Mechatronics is an interdisciplinary field, which has synergistically benefited from developments in the various engineering disciplines involved (Hewit, 1993). It has led to the development of intelligent products

* Corresponding author. Tel: +98-21-88602154

E-mail address: a.keyghobadi@hotmail.com (A. Keyghobadi)

C 2014 Growing Science Ltd. All rights reserved. doi: $10.5267 /$ j.ds1.2014.5.005 
that are flexible, accurate, and meet the changing needs of the consumer. Mechatronics technology therefore can be introduced as an appropriate alternative for product manufacturing.

Mechatronics is a synergetic combination of mechanical, electronic, and computer engineering; control systems; and information technology in designing and manufacturing industrial products and processes with high accuracy (Hewit, 1993). Mechatronic products are differentiated by the fact that some mechanical functions are replaced with electronics and software programs that provides high flexibility in terms of both design and operation. Increased speed and accuracy in operations along with "automatic navigation and troubleshooting" based on information received from the environments and the systems are other advantages of mechatronics. Moreover, mechatronic products are able to communicate and function in complex systems with distributed controls.

Agility can be increased in competitive environments by integrating the technical and technological aspects of design from the various branches of engineering involved in mechatronics by using a technique such as concurrent engineering. However, despite the fact that mechatronics is now an established branch of engineering, the software design and conceptual aspects have rarely been investigated in relation to other concepts such as agility, organization, and management. To predict and respond rapidly and effectively to the increasing customer needs and design complexity, the benefits of agile manufacturing as a production and construction method (philosophy) should be combined with mechatronics technology as the basis for design and development of products.

Mechatronic products were originally developed using the classic design models and design principles from some certain engineering fields. These models are either separate techniques or combined models, neither of which benefit from an integrated approach toward design and development. In separate models, the biggest drawback is the fact that each member of the development team employs various standard methods, which hampers teamwork and interdisciplinary design. The development experts have specific skills in their own functional fields, but often are not equipped with enough knowledge in a coworker's field. Obviously, in this case, components will be designed separately, regardless of the related requirements in other domains. Some of these models include the VDI-2221 (Verein, 1993) and VDI1-2422 (Verein, 1994) standards. The representative combined models are the waterfall and spiral models. The waterfall model, first described by Royce (1970) is a sequential model for the development of products. By linking its various levels through a feedback mechanism, it can be applied as an iterative model for developing software. The spiral model, first described by Boehm (1988), is a combination of two components-design and construction of a prototype at each stage. It attempts to combine the advantages of the top-down and bottom-up design approaches. In fact, the spiral model includes the features of waterfall model in the construction of a prototype at each stage. It provides better results, prevents duplication of effort, and saves on cost and time, making it a good option for project development and complex, large, and expensive products. This was not the first model that used a repeating loop for development, but was the first that highlighted the importance of an iterative loop. There are various characteristics for the models such as connection among involved fields, iteration of development cycle, and repeated testing to reduce risk.

The V-model is another integrated model used on the field of mechatronics for software development and can be considered as an extension of the waterfall model. Instead of moving linearly downward, the process moves upward after the implementation phase in a V-shaped form. One of the advantages of this development method is that each phase can be implemented using the complete details and documentation of the previous level (the advantage of the waterfall model), while the repeated tests (as in the spiral model) will identify the potential risks such as computational errors that can reduce customer acceptance and satisfaction. Thus, a verification and validation loop is created to prevent loss of time and expenses in identifying such problems at the final stages. 
The V-model is the current standard model for design and development of complicated engineering systems (Komoto \& Tomiyama, 2010). However, these previous authors propose a tool to eliminate unnecessary details in the design of components and subsystems, especially in conceptual design and construction of prototypes. This tool applies computer-aided design to simplify the physical relationships in the configuration of the product. Therefore, engineers from different fields can overlook the unnecessary details and design the system/product within the framework of geometric information with logical time intervals between steps. They showed that this could prevent many failures due to lack of design conformity among different domains. For this tool, identification of critical system components such as sensors and actuators plays essential role for designers of various fields, although every designer may also consider different details of such items. Hehenberger et al. (2010) also introduced the V-model as the primary basis for the design of mechatronic systems, but at the same time pointed out that traditional design system in this field are time-consuming. In order to solve the problem, they developed a hierarchical model for effective communication between different fields. In their solution, all modules and components, in accordance with their type, are placed into a particular area that can be a combination of one or more engineering domains (i.e., electromechanics, electromagnetic, thermodynamics, system control, etc.). In order to prevent errors and repetition of loops in the V-model, necessary communication and coordination is built within each area and among the areas involved in the design of each component. Finally, these areas are connected to each other through the main layer (the mechatronic layer) to form a hierarchy. This main layer may contain separate categories. Their study showed that although this model cannot completely prevent the repetition of loops, it may prevent many of them from at the low levels of design in the inner and main loops.

Gausemeier et al. (2011) again pointed out the interdisciplinary nature of mechatronic design and emphasized the necessity of coordination and synchronization of the various domains involved in the design and development process through effective communication. Although they were mainly concerned with providing a three-cycle model for the integration of conceptual design and development process with the production system, and apart the fact that V-model is applied to both design and production, what motivates us most is the second and third cycles of the model. In these cycles, a computerized prototype or virtual product is used for integration of design with virtual production in a digital factory. This is a convenient method for preventing repeated failure because it may become incompatible with designs in different fields within the capabilities and limitations of the available production technology. Virtual design, especially in the construction of a prototype can be considered as one of the ways to avoid unnecessary details, particularly at the component level, although the relations and physical details of the main configuration also will be of importance. The first cycle also emphasizes the need to ensure the success of the design in the future and points to creativity techniques, including the TRIZ technique for converting new ideas into products and for solving problems and the Delphi method or trend analysis for identifying the probability of the success. As shown in Fig. 1, Seyedhosseini and Keyghobadi (2010) presented the evolutionary trend design and development models from other engineering fields used in mechatronics and it is based on the definitions of the key concepts of mechatronics presented by Hewit (1993).

These models preserve the advantages, eliminate the disadvantages of the previous versions, and include concepts such as concurrent engineering to integrate different related fields. However, these models cannot fully ensure integrated designs and features for the components, particularly at conceptual and preliminary design stages. With increasing complexity of design at the component level relative to the system and subsystem levels, integration among the components designed using principles from different fields requires frequent, time-consuming, and costly revisions. Spreading such non-compliance with design requirements to other levels will constrain the search for newer and more creative ideas at the system/product level. This reduces the agility of manufacturers to respond to customer's needs. Meanwhile, the same has been the goal of using mechatronics for creating competitive advantages. 


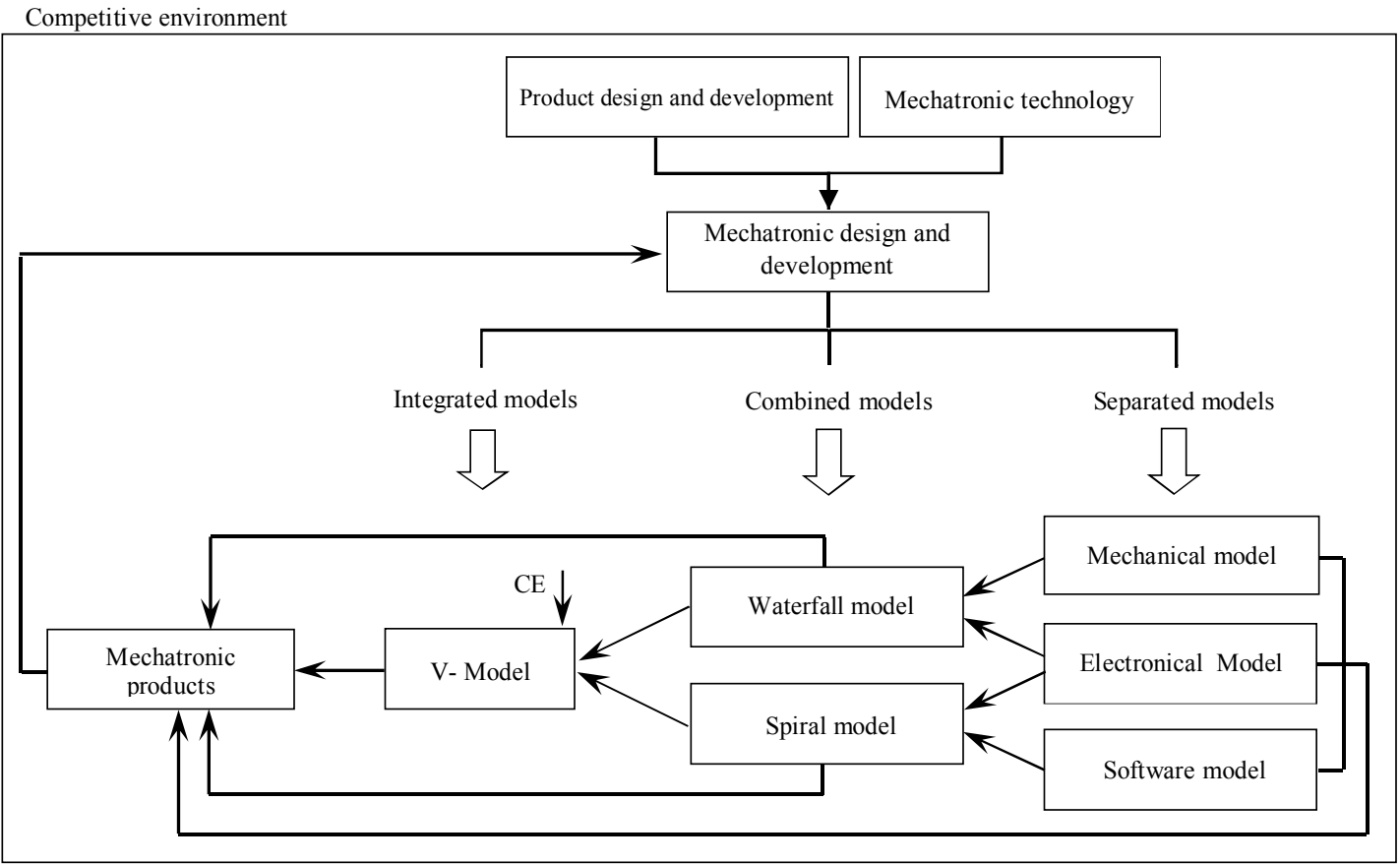

Fig. 1. Evolutionary trend of design and development models in mechatronics (Seyedhosseini \& Keyghobadi,2010)

In this study, we develop a model to integrate various fields involved in the design and development process of mechatronic products, which allows agile response to the changing needs and unpredictability of the competitive environment. Thus, the proposed model allows the design team to test multiple ideas in less time and with minimum possible costs.

\section{Theory}

Seyedhosseini and Keyghobadi (2010) identified the basic requirements and features of the proposed model called the $\mathrm{W}$-model shown in Table 1 based on 12 effective factors in design and development of products. Moreover, in developing the proposed model, agility enablers should be included to meet the growing challenges in today's competitive environment. These enablers require coordinated and interactive changes in four types of agility providers associated with the technology management model, as listed in Table 2.

There are two fundamental questions: How can the required agility be realized in mechatronics using the concepts of agile manufacturing? and what is the structure of the model that can integrate the design processes in various fields involved in mechatronics product development?

With regard to the conducted studies, the theoretical framework of the present study is presented in Fig. 2. In terms of the objective of the research, it is essential to study critical specific potentials and capabilities of this field because of various aspects involved in mechatronic technology, to determine the aspects and providers of agility for production in competitive environments, and to specify the process of the relationship of these two factors with each other. Therefore, the models employed in the design of mechatronic products are examined in the entire cycle of product development, so that the requirements of the proposed model of the research could be revealed. Finally, based on these specifications and by considering the factors effective in creating integration and agility during the process, we develop an integrated model for designing and developing mechatronic products within 
the framework of agile products for dynamic competitive environments. The results of such studies for determining the main structure of the model are termed Integrated Mechatronic modeling approach for Agile manufacturing in a Competitive environment (IMAC).

\section{Table 1}

Comparison of existing models for determining the features of the proposed model (Seyedhosseini \& Keyghobadi,2010)

\begin{tabular}{|c|c|c|c|c|}
\hline \multirow[b]{2}{*}{ Comparison factors } & \multicolumn{4}{|c|}{ Types of models } \\
\hline & $\begin{array}{l}\text { Separated } \\
\text { (Classic) }\end{array}$ & $\begin{array}{c}\text { Combined } \\
\text { (Waterfall - Spiral) }\end{array}$ & $\begin{array}{l}\text { Integrated } \\
(\mathrm{V} \text {-model })\end{array}$ & Suggested Model \\
\hline $\begin{array}{l}\text { Approach to meeting design } \\
\text { requirements }\end{array}$ & Partial & Middle partial & System (eliminating needs) & $\begin{array}{l}\text { Supra-system } \\
\text { (environment) }\end{array}$ \\
\hline Design method & Domains & Common & Inter-disciplinary & Integrated \\
\hline $\begin{array}{l}\text { Design adaptation } \\
\text { (Test \& Integration) }\end{array}$ & Rare \& Slightly & Casual & Gradual & Concurrent \\
\hline Documentation & Much \& Unrelated & Consumedly \& Lengthy & Surplus \& Unnecessary & Relevant and necessary \\
\hline $\begin{array}{l}\text { Design, construction, and } \\
\text { testing of prototype }\end{array}$ & -------- & $\begin{array}{l}\text { Expensive \& time- } \\
\text { consuming (Multiplicity } \\
\text { of excessive Prototype) }\end{array}$ & $\begin{array}{l}\text { Expensive \& time-consuming } \\
\text { (Unnecessary steps) }\end{array}$ & $\begin{array}{l}\text { Quick \& Inexpensive } \\
\text { (Simulation tools) }\end{array}$ \\
\hline $\begin{array}{l}\text { Design Domain } \\
\text { (Risk analysis) }\end{array}$ & Discrete & Synthetic & Components and integration & Integrated design \\
\hline Test design & Casual \& Simple & Multiple \& Difficult & Continual \& Complex & Logical and systematic \\
\hline $\begin{array}{l}\text { Need to hierarchy } \\
\text { (Systems, subsystems, } \\
\text { components) }\end{array}$ & No & No & Yes & Yes \\
\hline $\begin{array}{l}\text { Adaptation to new } \\
\text { requirements }\end{array}$ & --------- & Limited \& Long & Active \& inopportune & Proactive $\&$ agile \\
\hline $\begin{array}{l}\text { Acceptance risk } \\
\text { (System - product) }\end{array}$ & Too much & Much & Low & Minimum \\
\hline Maintenance & $\begin{array}{l}\text { Complex and specialty } \\
\text { (Manufacturer) }\end{array}$ & $\begin{array}{l}\text { Technical and difficult } \\
\text { (Representative) }\end{array}$ & $\begin{array}{l}\text { Intelligent \& Quick } \\
\text { (Repairman) }\end{array}$ & $\begin{array}{l}\text { Intelligent and simple } \\
\text { (User) }\end{array}$ \\
\hline $\begin{array}{l}\text { Combination of creativity and } \\
\text { innovation resources } \\
\text { (Professionals, experts, } \\
\text { customers) }\end{array}$ & ------- & --------- & Limited & Widespread \\
\hline
\end{tabular}

Table 2

Main components and factors for developing the proposed $\mathrm{W}$-model

\begin{tabular}{|c|c|c|}
\hline Component & Main factors & References \\
\hline $\begin{array}{l}\text { Challenges of the } \\
\text { competitive environment }\end{array}$ & $\begin{array}{c}\text { Need for rapid commercialization, market globalization, information and } \\
\text { services, resources and environment }\end{array}$ & $\begin{array}{l}\text { Clark \& Fujimoto(1991), Souder \& Moenart(1992), Sharif \& } \\
\text { Zhang (2001), John et al. (2001), Martins(2003) }\end{array}$ \\
\hline Agil ity enablers & $\begin{array}{l}\text { Quick prototyping, concurrent engineering, teamwork, empowerment of } \\
\text { employees, flexible and multi-skilled personnel, virtual organization, } \\
\text { change and risk management, continuous improvement, focusing on core } \\
\text { capabilities }\end{array}$ & $\begin{array}{l}\text { Lo(1998), Yusef et al.(1999), Sharp et al.(1999), Zhang \& } \\
\text { Sharifi(2000), Christopher (2000), Yang \& Li(2002), Giachetti et } \\
\text { al.(2003),Zain et al.(2005), Swafford (2006),Lin et al.(2006), } \\
\text { Agarwal et al.(2007) }\end{array}$ \\
\hline Agility providers & $\begin{array}{l}\text { Organization (organizational structure), human resources, technology, } \\
\text { innovation and creativity }\end{array}$ & $\begin{array}{l}\text { Goldman \& Nagel(1993), Bullinger(1999), Christopher (2000), } \\
\text { Harrison \& Van Hoak(2005), Ramesh \& Davidson (2007) }\end{array}$ \\
\hline Technology management & $\begin{array}{l}\text { Value creation, quality and cost, reaction capability, agility, innovation, } \\
\text { integration, environment }\end{array}$ & $\begin{array}{l}\text { Betz et al.(1995), Gatignon \& Xuereb (1997), Fontes\& Coombs } \\
\text { (1997), Zahra \& Bogner(2000), Khalil \& Hazem(2005), Y in } \\
\text { (2002), Adner \& Levinthal(2002), White \& Bruton(2007), } \\
\text { Campos (1999) }\end{array}$ \\
\hline
\end{tabular}

\subsection{Conceptual Model}

As shown in Fig. 3, the conceptual model is started from the existing V-model. The approach aims to simultaneously preserve the benefits of other previous models while making as many modifications as possible for integration and agility. There are two rules considered for conducting these modifications:

- The necessity to accelerate testing at the system/product level (base idea) for rapid and timely compliance with changes to requirements.

- Establishing a mechanism for systematic and continuous communications among involved fields from the first step (conceptual and preliminary design). 


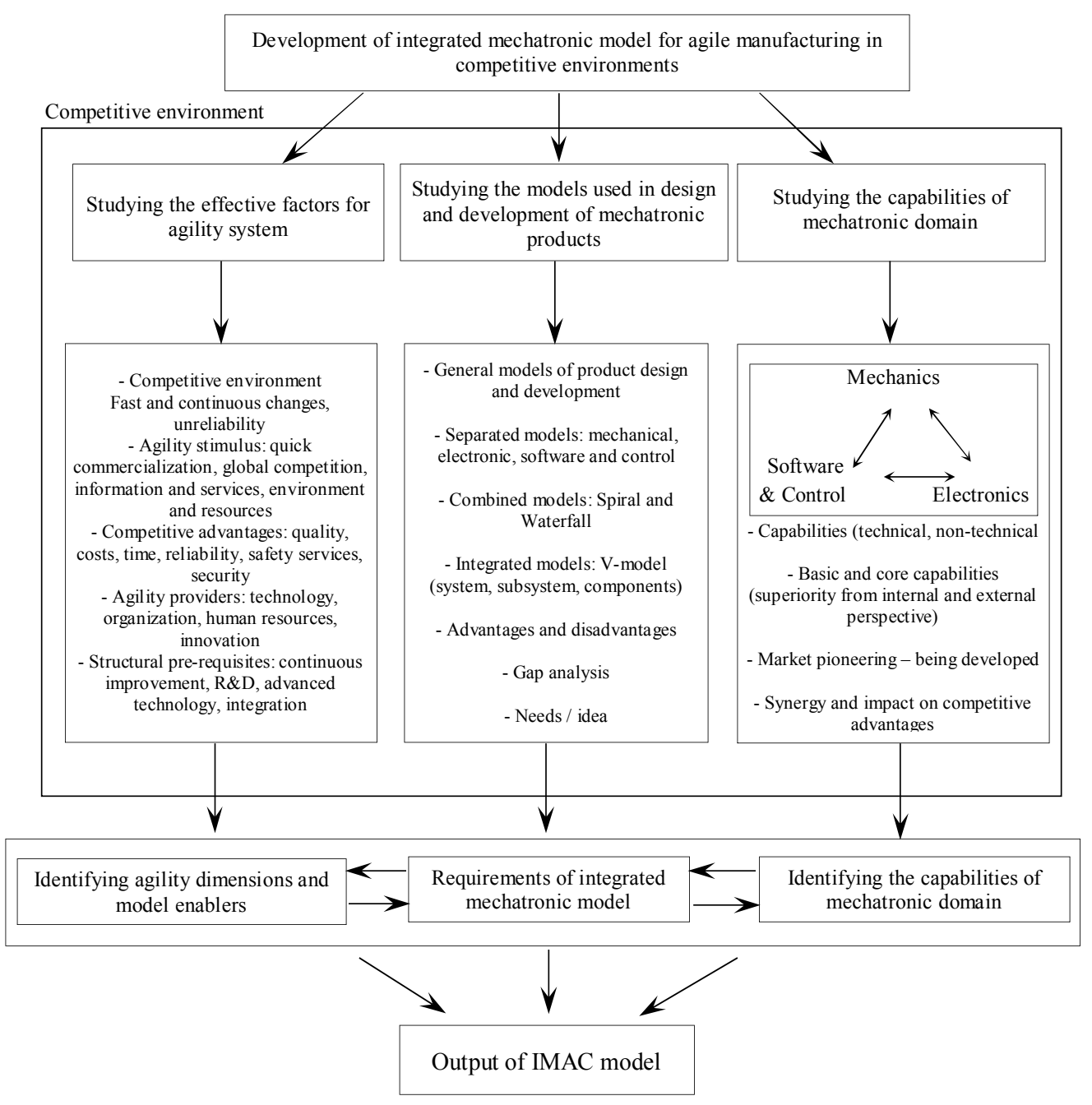

Fig 2. Development process for integrated mechatronic production model for agile manufacturing in competitive environments

\subsection{Proposed Model}

To explain the principles of model development in this study, we describe the following three major stages.

\subsubsection{Virtual Prototype Simulation}

This stage is important from two perspectives: First, the relative cost of the changes to product design and concepts at this stage is small. Second, since the process of testing new ideas is flexible and cheap, changes to respond to market demands can be continuously included in new generations of products (Bhuyar, 2000). However, failure to properly understand the needs at these early stages (conceptual and preliminary design) can increase the cost and the time spent on repair and maintenance between 50 to 200 fold (McConnel, 1996). 


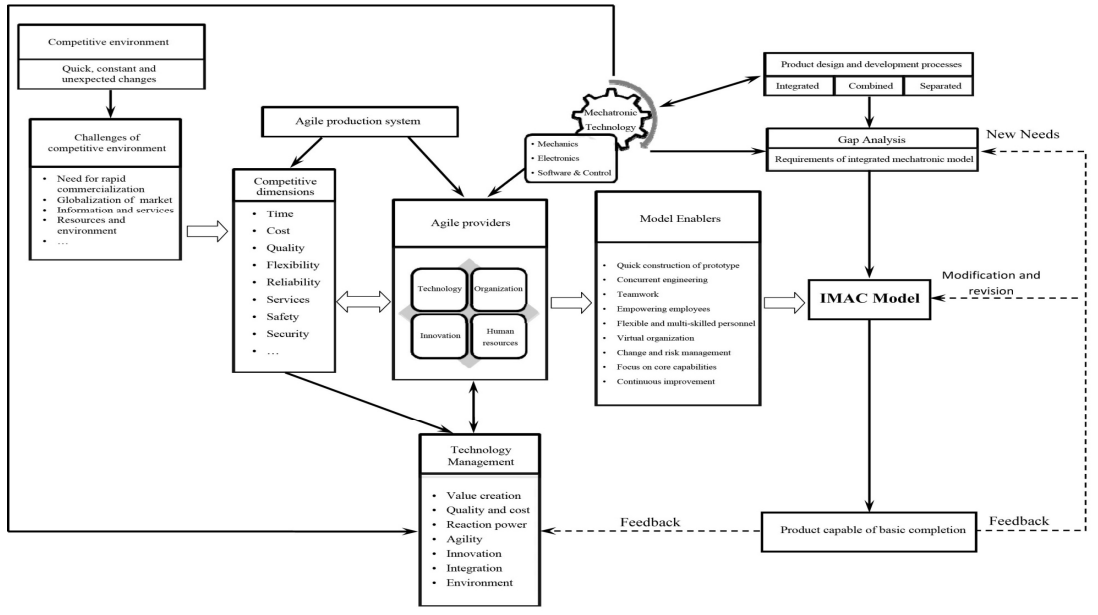

Fig 3. Conceptual model

From the schematic of the V-model loop (Fig. 4), it can be seen that the design correctness at the system level is delayed until the last stages of the product development. The spread of such failures to other levels (subsystems and components) and the lack of common control factors among such designs will only make integration and testing long and costly (Fig. 5). However, what is important in making a prototype is verification of the basic concept of the product at the system level, not its components. To overcome these problems, we consider the use of simulation methods. In particular, the LEGO simulator was selected because it is a fast simulator that includes a variety of prefabricated parts and fittings, which can be easily combined with other modules. With this simulator, component-level parameters were eliminated from the prototype development process.

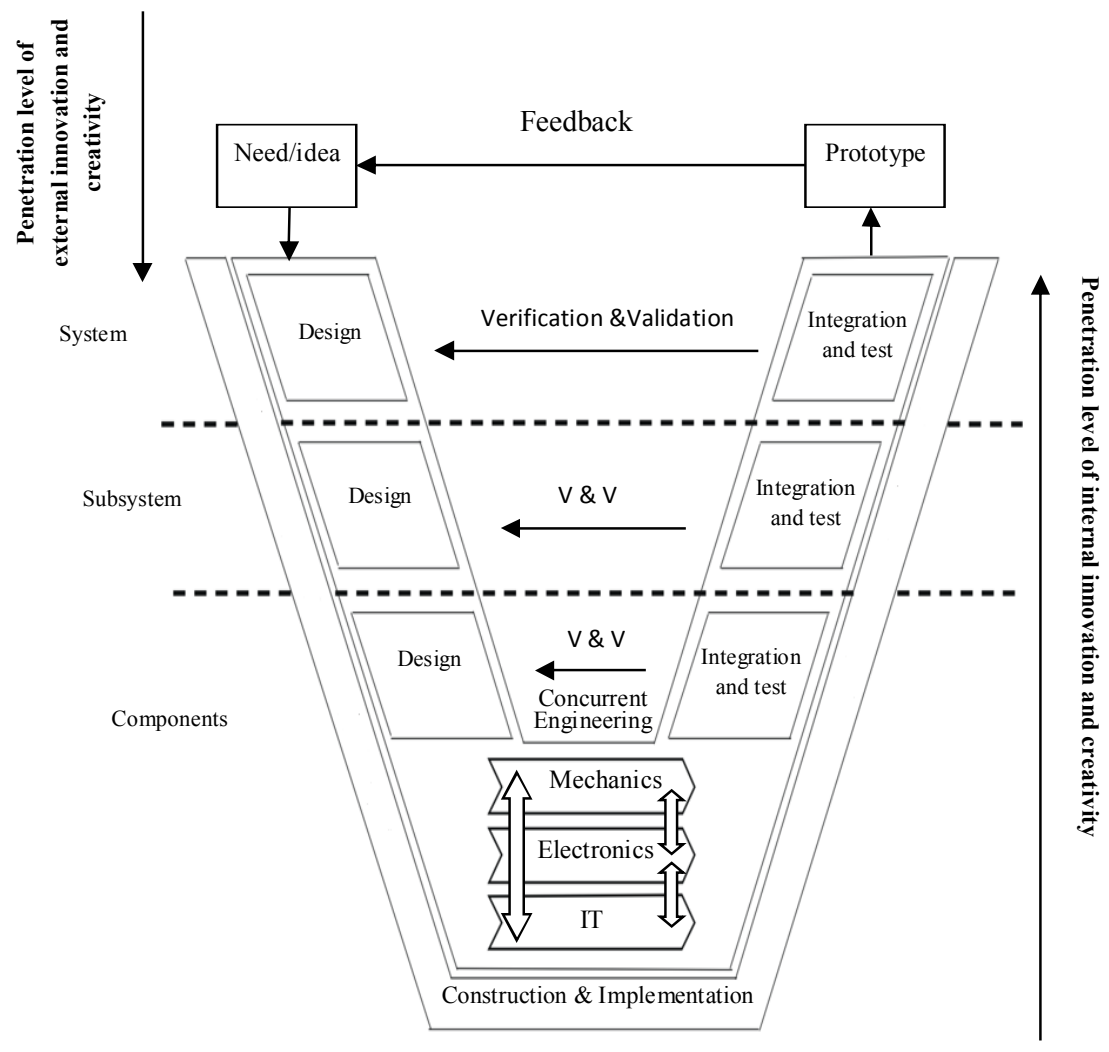

Fig 4. Iterative loop of V-model for design and construction of the prototype (Verein, 2004) 


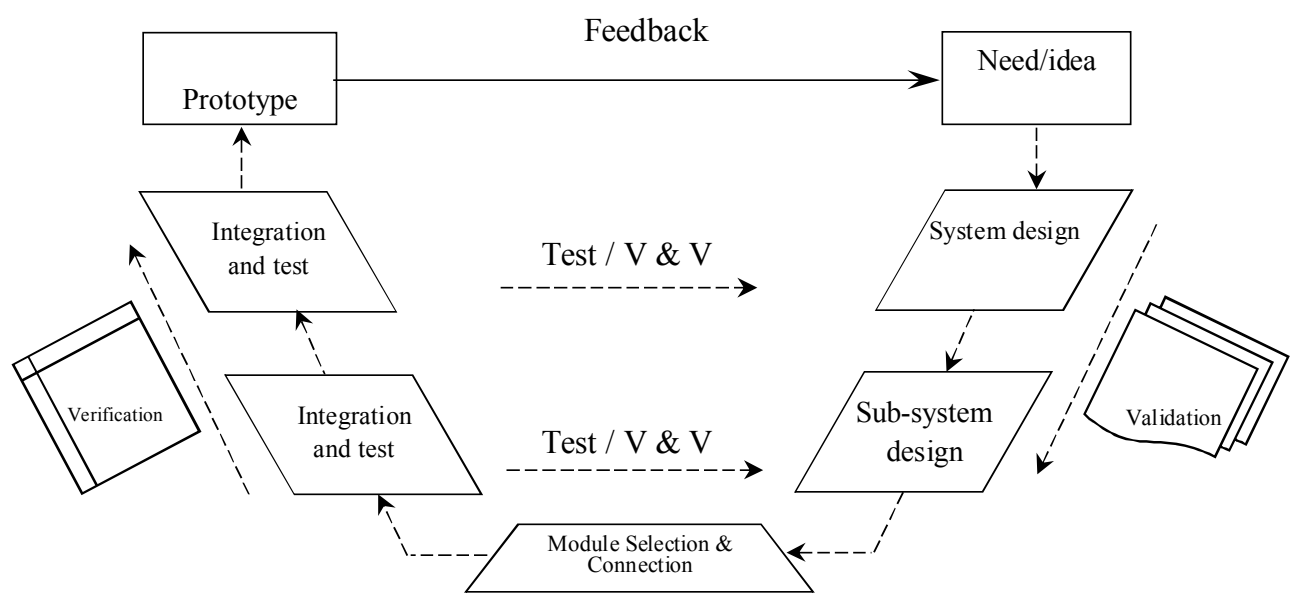

Fig 5. Repeating the loop of V-model for finalizing a product

This prevents design problems from reaching the critical levels of product development, and consequently, requires fewer revisions for integration at this level; moreover, the speed of testing new ideas and the number of such ideas tested is much greater (Fig. 6). This rapid prototyping allows quick and cheap testing of the main concepts to meet revised requirements.

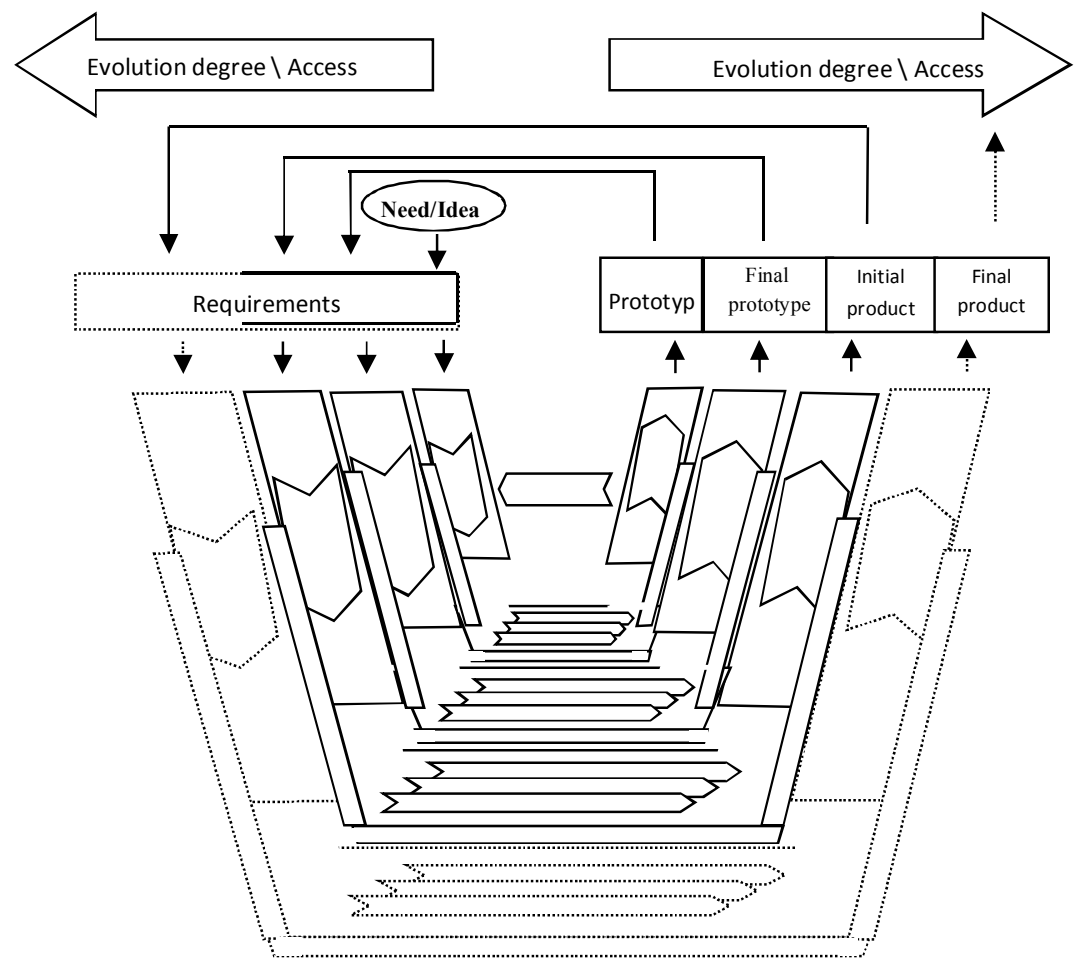

Fig 6. Iterative loop of the model for design and development of the prototype (Gausmeier, 2002)

\subsubsection{Creating the Interdependency Umbrella}

Concurrent engineering fails to achieve integration despite establishing communications among different fields (Verein, 2004). Hence, there is a need for a new type of communication among such fields. Because of the interdisciplinary nature of mechatronics, designers and engineers must be familiar 
with the broader range of sciences (Hewit, 1993). Thus, instead of the concurrent engineering approach of establishing cross-divisional communication (Agarwal, 2000), we propose to set up of an integrated team of diverse experts with continuous communications due to interdependency between their areas of expertise. Forming this team from the first design step will reduce non-compliance of the designs or risk of failure in the testing and integration steps. This should reduce design time and cost and allow quicker delivery of the product to the market (Fig.7).

It should be noted that the prerequisite for forming the team is determination of the common design aspects, i.e., interdependency among fields. There are two major groups of dependencies: the technical considerations, which include sensors and operators, and the human-machine interaction parameters. Any change or modification to any of these sections, should be agreed upon by all team members. Thus, for each type of system, specific and precise checklists should be separately prepared in terms of design specifications associated with revision needs in each dependency group.

By creating this umbrella, we can expect that the in-depth knowledge of experts in a field would be strengthened in relation to their capabilities and limitations in other fields. This should reduce inconsistencies among the designs. Accordingly, in the proposed research model, an interdependency umbrella is introduced along with specific checklists for each group of dependencies across all stages of design.

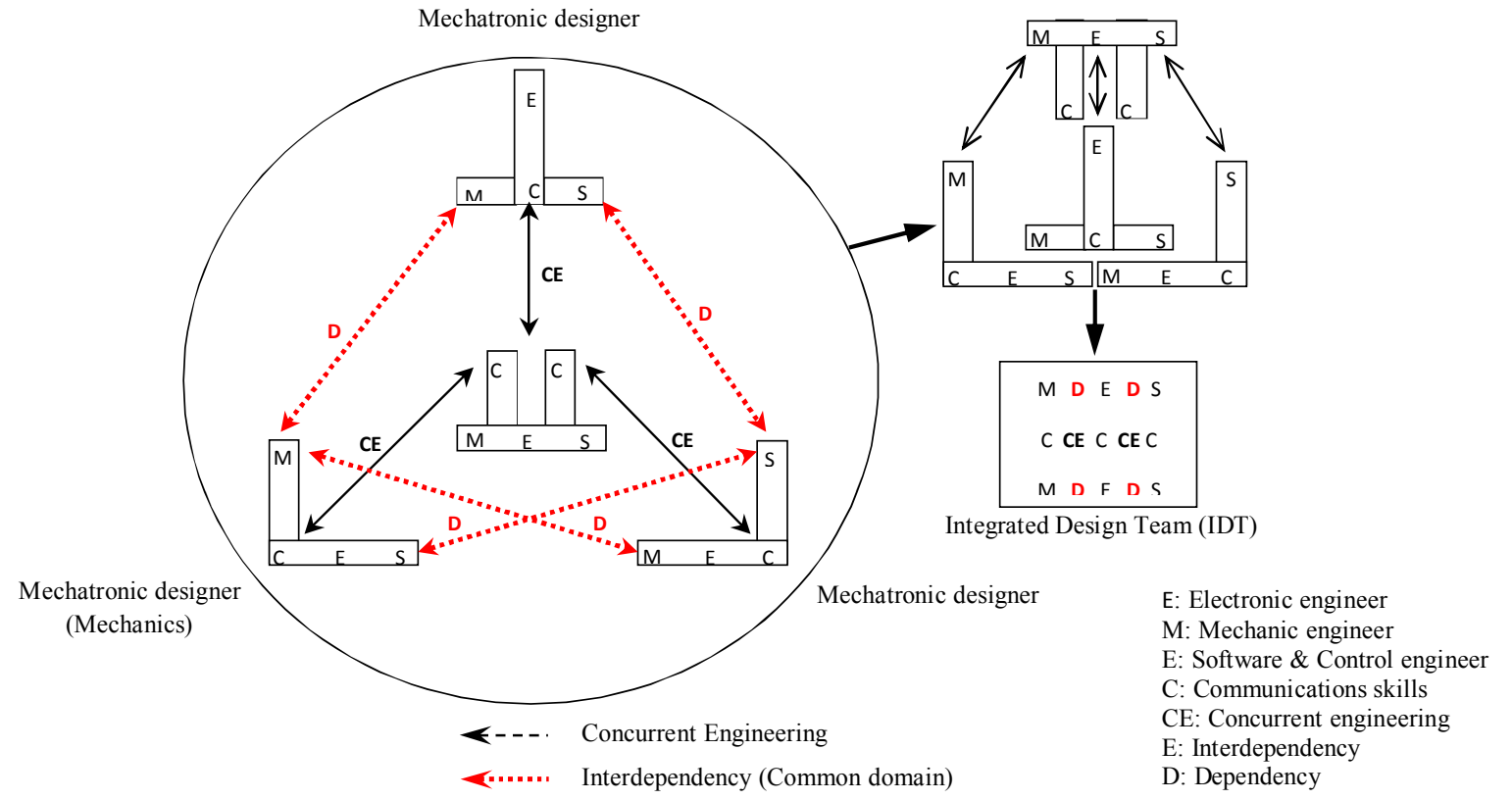

Fig. 7. Structure of integrated team and required knowledge fields for mechatronic designers

This change ensures integrity is maintained among the various fields and simultaneously allows easy design modification and provides the needed human resources in order to reduce the risk of failure (error) of the frequency of design and integration tests.

\subsubsection{Proactive Approach toward Consumer Needs}

The combination of virtual prototype simulation and an appropriate context for communication between the involved fields in an integrated design team will allow the design of new models not only combine innovations from each team (internal resources) but also make use of market knowledge 


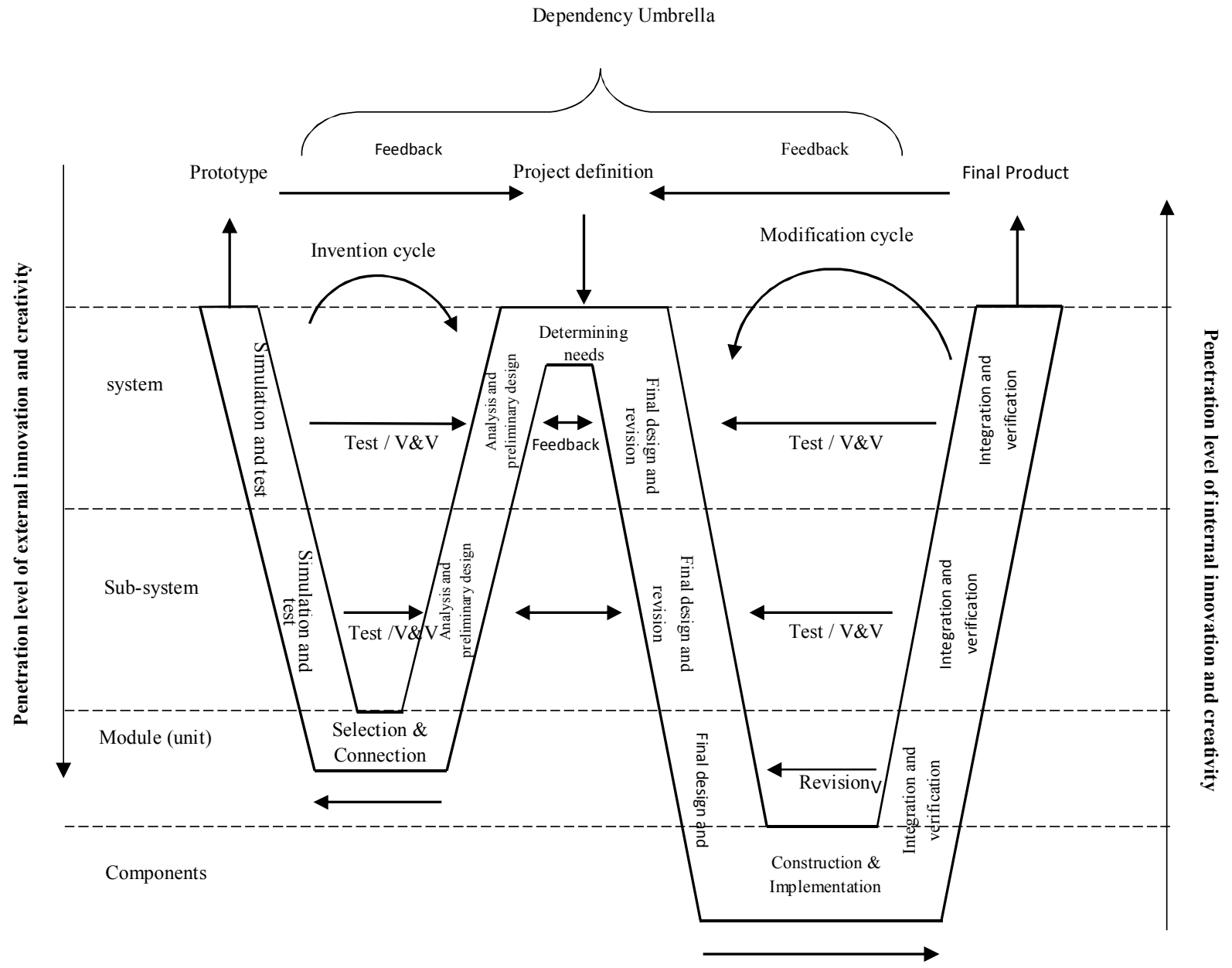

Fig. 8. Proposed W-model for integrated and agile design and development of mechatronic products

behavior toward consumer needs and, consequently, can reduce consumer acceptance risk. Because of its similarity with the letter W, as shown in Fig. 8, the proposed model is called the W-model.

\section{Material and Methods}

The proposed methodology was compared against the V-model using a case study involving the design of industrial robots. Specifically, we consider the mean time require to design and build a prototype of a Hyper Line Tracer robot in this study. Considering a maximum error of 10 days and a level of confidence of $95 \%$, the required sample size can be calculated as follows:

$n_{\mu}=\left(\frac{Z_{\alpha / 2} \cdot \sigma_{x}}{e}\right)^{2}$,

Where $n_{\mu}$ is the sample size, $\alpha$ is the level of significance, $Z_{\alpha / 2}$ is the standard normal value, $e$ is the maximum permissible error, and $\sigma_{x}$ is the standard deviation.

$\sigma_{x}=\frac{\operatorname{Max}-\operatorname{Min}}{4}$ 
where Max is the maximum time and Minis the minimum time in days. It should be noted that experts require 3-7 months to design and construct such a prototype robot. According to the available information we have $\sigma_{x}=30, \mathrm{e}=10, \alpha=0.05 \mathrm{Z}_{\alpha / 2}=1.96, \mathrm{n}_{\mu}=34.57 \approx 35$. Thus, the sample size for each of the two groups was set to 35 robots. Furthermore, to control for various extraneous factors, we have employed a laboratory environment, which allows more control and high inherent validity. However, because such an environment will differ from the reality, the results cannot be widely generalized; this can be mitigated by compliance of sample with community and ensuring that the test conditions match the real environment. Therefore, in this study, with respect to the required controls, the experimental plan was as follows:

The hyper tracer robots are designed with the similar objective to follow linear defined traces, and are often used in factories, hospitals, stores, and libraries. In this test, seven teams with four members, and 14 pairs of teams have been used. Each group had to design five robots or modify the previous robots, in which the cost and the time involved in the design of the previous robot is included. All teams were aware of the research objectives and exact structure of each of the models. Moreover, all teams were fully monitored and were provided similar conditions in terms of location, equipment, and supplies. It was noted that fatigue or judgment would not bias the results. From the results, the cost, time, and frequency of design revision at different levels of the process were calculated. Then, the validity of the two models was determined based on the Spearman correlation coefficient. Finally, the Analyse-it add-in software in Microsoft Excel (Microsoft Corp., Seattle) was used to conduct median comparison tests of cost, time, and revision frequency for both the two models.

\section{Results}

After conducting the case study, we calculated the time and resources spent by the teams to design and construct the robots using each model, as shown in Fig. 9 and Fig. 10.

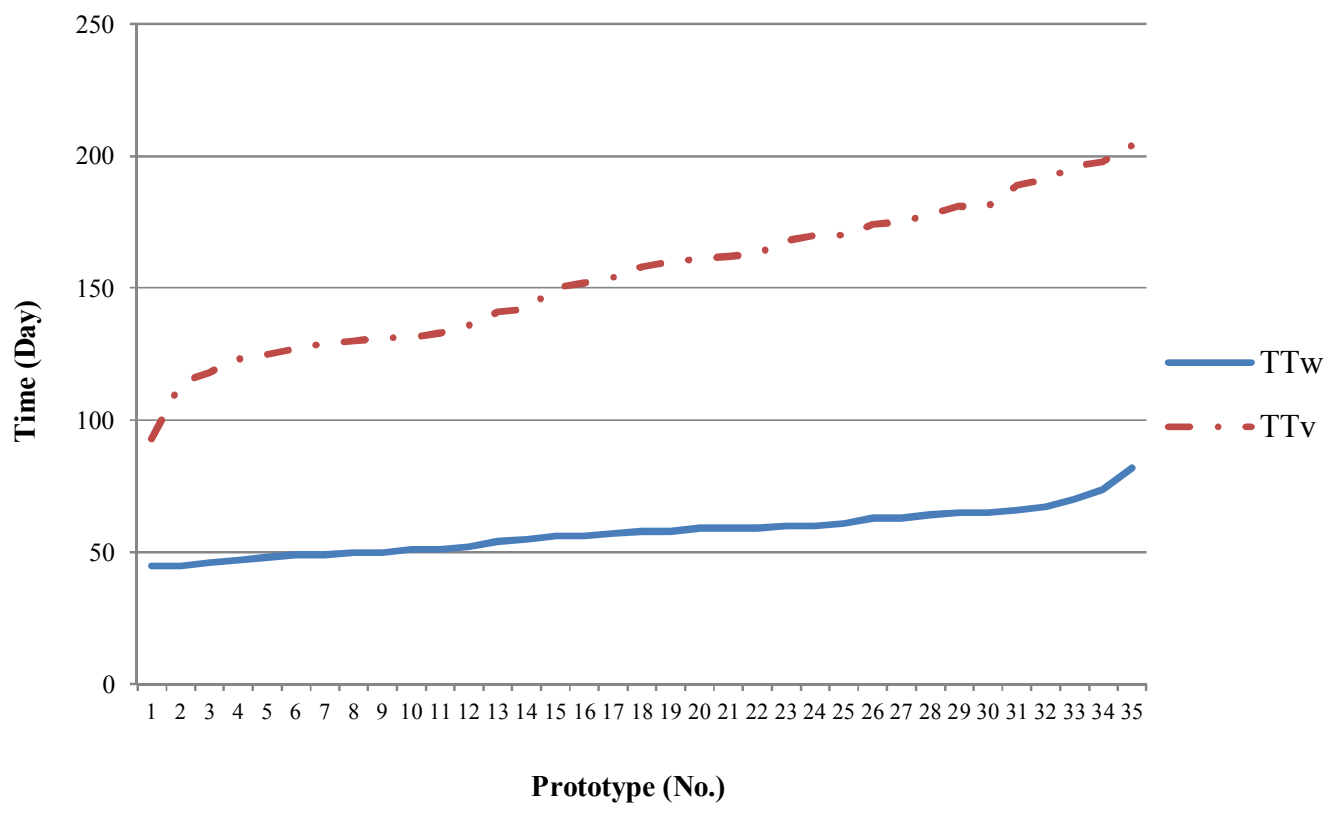

Fig. 9. Comparing the spent time for design, construction, or simulation of hyper tracer robot prototypes based on V-model and W-model 


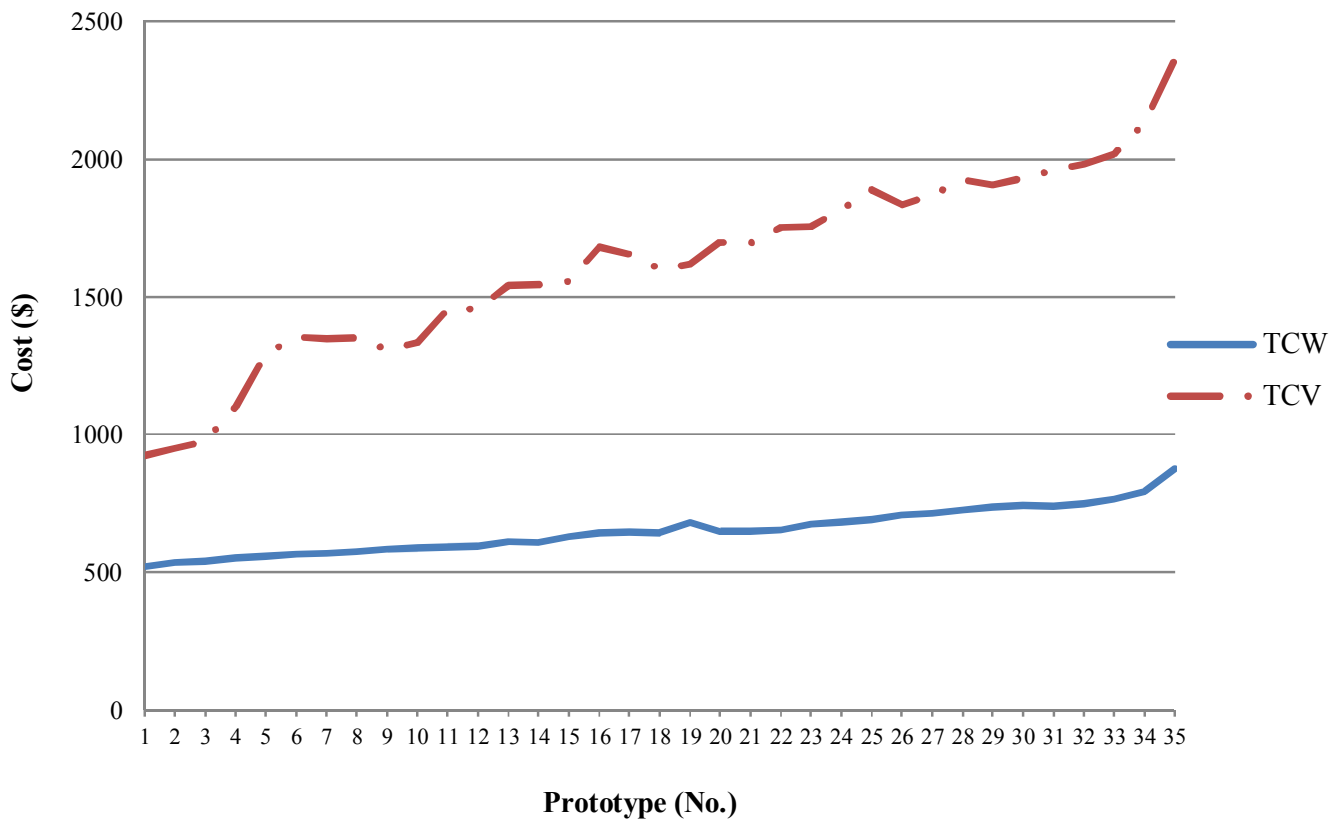

Fig. 10. Comparing the costs for design, construction or simulation of hyper tracer robot prototypes based on V-model and W-model

From these results, the mean time and variance of both the two groups were calculated, as shown in Table 3:

Table 3

Results of design and construction time of prototypes using V-model and W-model.

\begin{tabular}{lllllll}
\hline & & \multicolumn{3}{c}{ Development model } & & \\
Tested quantity & Statistic & V-model & W-model & Statistic Z & Critical value & \\
\hline Time (day) & Mean & 58 & 155 & & & $\mathrm{H}_{0:} \mu_{\mathrm{v}} \leq \mu_{\mathrm{w}}$ \\
& Variance & 72.90 & 738.79 & $\mathrm{Z}_{0}=2.14$ & $\mathrm{Z}_{\alpha=0.01}=2.33$ & $\mathrm{H}_{1:} \mu_{\mathrm{v}}>\mu_{\mathrm{w}}$ \\
\hline
\end{tabular}

As shown in the Table 3, the calculated $Z$ statistic is 20.14.Comparing it with the critical value and rejecting the null hypothesis at the $99 \%$ confidence level, we conclude that the $\mathrm{W}$-model is faster than the $\mathrm{V}$-model. Based on the results of design and construction of robots, the mean costs and variance for both the groups were calculated, as listed in Table 4.

Table 4

Results of design and construction costs of prototypes using V-model and W-model

\begin{tabular}{lllllll}
\hline & & \multicolumn{3}{c}{ Development model } & & \\
\cline { 3 - 4 } Tested quantity & Statistic & V-model & W-model & Statistic Z & Critical value & \\
\hline Costs $(\$)$ & Mean & 1616 & 651 & & & $\mathrm{H}_{0:} \mu_{\mathrm{v}} \leq \mu_{\mathrm{w}}$ \\
& Variance & 116141.79 & 6890.91 & $\mathrm{Z}_{0}=16.28$ & $\mathrm{Z}_{\alpha=0.01}=2.33$ & $\mathrm{H}_{1:} \mu_{\mathrm{v}}>\mu_{\mathrm{w}}$ \\
\hline
\end{tabular}

The calculated $Z$ statistic is 16.28. Comparing it with critical value and rejecting the null hypothesis at the $99 \%$ confidence level, we conclude that the $\mathrm{W}$-model simulates the prototype at a lower cost than the V-model. Next, the number of revisions due to error (failure) or for testing new ideas was determined, as shown in Fig. 11. 
Based on the results, the mean number of revision and variance for both the groups were calculated, as listed in Table 5.

Table 5

Results from developing tracer robot using V-model and W-model

\begin{tabular}{lllllll}
\hline & & \multicolumn{3}{c}{ Development model } & & \\
Tested quantity & Statistic & V-model & W-model & Statistic Z & Critical value & \\
\hline Costs $(\$)$ & Mean & 31 & 46 & & & $\mathrm{H}_{0:} \mu_{\mathrm{v}} \leq \mu_{\mathrm{w}}$ \\
& Variance & 14.97 & 21.07 & $\mathrm{Z}_{0}=14.78$ & $\mathrm{Z}_{\alpha=0.01}=2.33$ & $\mathrm{H}_{1:} \mu_{\mathrm{v}}>\mu_{\mathrm{w}}$ \\
\hline
\end{tabular}

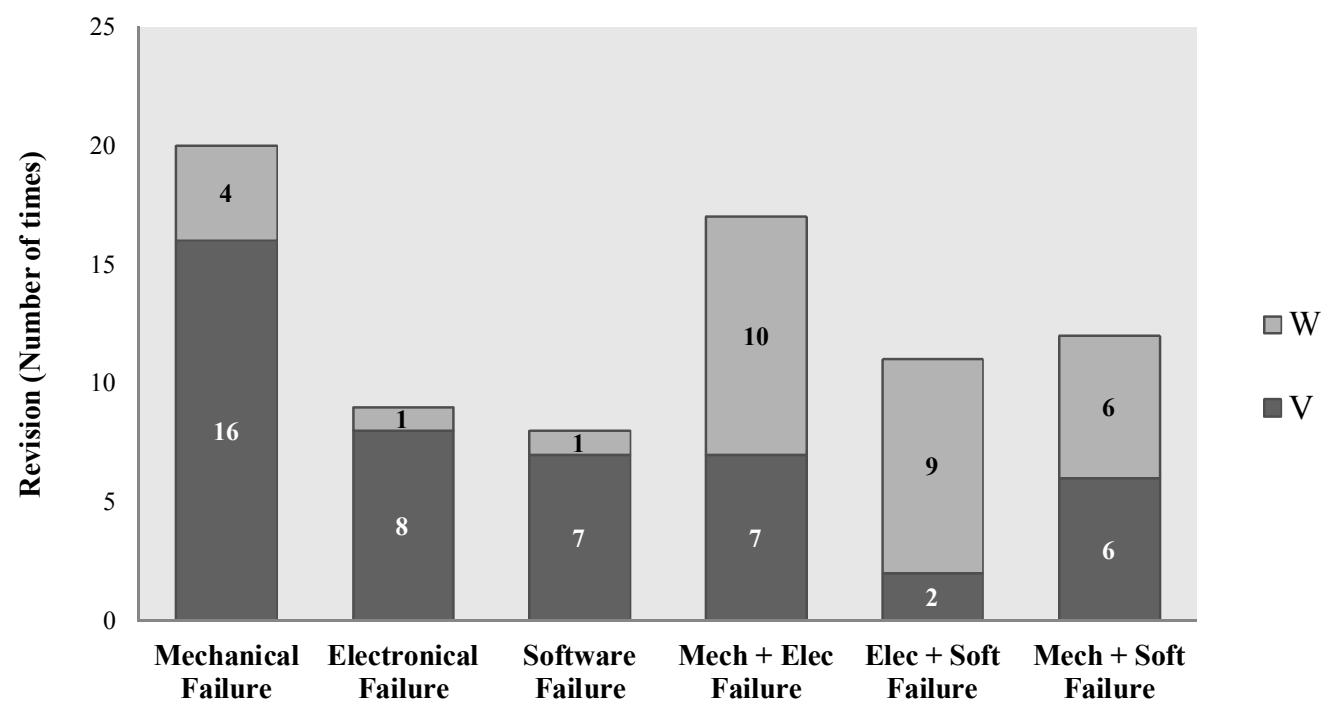

Fig. 11.Change in distribution revisions for design using V-model and $\mathrm{W}$-model

Comparing the calculated statistic (14.78) with the critical value and rejecting the null hypothesis at the $99 \%$ confidence level, we conclude that the W-model has higher integrity and consequently less failure than the $\mathrm{V}$-model and allows testing of more ideas. With regard to the distribution and concentration of the errors using the two model, as shown in Fig. 11, it is evident that in the V-model, the focus of revisions is at the component level and these revisions mainly stem from non-compliance with design requirements at other levels (error or failure). However, in the W-model, the focus of revisions is at system level, which indicates that more ideas from internal and external resources were tested. Ultimately, this ensures less risk in the final design and greater consumer acceptance of the final product.

To further validate the findings, we consider the Spearman correlation coefficient based on the following assumptions for the V-and W-model:

$H_{0}=$ There is no significant correlation between the results of test groups.

$H_{1}=$ There is a significant correlation between the results of test groups.

$r_{s p}=1-\frac{6 \sum d_{i}^{2}}{n^{2}-n}$ 
where $d_{i}$ is the difference between the ranks of groups, and $n$ is the number of total subjects (groups).

We calculate this value for the $\mathrm{V}$ - and $\mathrm{W}$-models by referring to the information in the tables. Thus, we can determine the probability $P$ for the occurrence of $H_{0}$ for testing a range based on the greater than or equal values of calculated $r_{s p}$ coefficient. If this value is smaller than $\alpha=0.01, H_{0}$ can be rejected in favor of $H_{1}$, indicating a significant correlation between the results of the test groups. From

our results, we have $r_{s p-W}=0.994$ and $r_{s p-V}=0.990$. With regard to the correlation coefficient calculated for each model, the probability in both cases is $P=0.000$, which is smaller than $\alpha=0.01$. Hence, the $H_{0}$ hypothesis can be rejected in favor of $H_{1}$. Thus, it can be concluded that there was a significant correlation between the results of the samples in both groups and therefore both models are valid.

\section{Discussion and Conclusions}

In short, it can be noted that other similar studies (Komoto \& Tomiyama, 2010 ; Gausemeier et al. 2011) also have tried to provide some solutions in order to avoid unnecessary details of design, especially in the preliminary and conceptual stages. This is an important factor in the repeated, costly and time-consuming failures of V-model. For example preparing a computerized model of the product or simplification of the physical relations of the configuration of the product can be mentioned. Other efforts have also been devoted to identification of common areas of design among different fields and their inter-dependencies for strengthening the communication in such areas. In this connection, the importance of identification of some parameters such as sensors and actuators in presenting architecting tool of system or hierarchical relation between such shared areas can be cited. Moreover, the necessity to access creativity resources and a wider range of ideas in form of product and also to be ensured of the success of the design can be referred to, and using some technique such as TRIZ technique or the Delphi method can be mentioned (Gausemeier et al. 2011).

By employing virtual prototype simulation, several complex and unnecessary details in design and integration at the component level could be eliminated. This significantly reduced time and cost and provided an environment for simultaneous and synergistic combination of creativity and innovation from internal and external resources. It also increased the number of tested ideas at the system level. In addition, to identify the common design aspects among fields and to determine the interdependency among them, an integrated team was formed for product design and development. Coordination among team members for continuous and systematic design revision was accomplished using interdependency checklists in each project. This provided a supportive umbrella over all stages of design. This strategy also prevented non-compliance of design requirements in different fields, saved time, and reduced costs and the risk of error (failure) at other stages of the process. The experiment with the hyper tracer robots confirmed better consistency and agility of the proposed model. However, it should be noted that these models were investigated and tested for the design and simulation of a certain type of industrial robot. Thus, the results are limited to the conditions of the pilot experiment. Therefore, these models should be compared for different products with different levels of complexity.

\section{References}

Adner, R., \& Levinthal, D. (2004).The emergence of emerging technologies. California Management Review, 45(1), 35-70.

Agarwal, A., Shankar, R., \& Tiwari, M.K. (2007). Modeling agility of supply chain, Industrial Marketing Management, 36, 50-61. 
Agarwal, M.(2000). Manufacturing integration under Mechatronic banner; Agile engineering : search of new path to excellence. Tech India publications, New Delhi.

Betz, F., Key, L.K., Khalil, T., \& Smith, R. (1995). Management paradigms and the technology Factor. Technology Management, 1, 17-25.

Bhuyar, C. R. (2000). Mechatronics: An integrated approach to product development; Agile engineering: search of new path to excellence, Satya parakashan ( Tech india publications), New Delhi .

Boehm, B.W. (1988). A Spiral Model of Software Development and Enhancement, IEEE Computer Society Press Los Alamitos, CA, USA.

Bullinger, H. (1999). Turbulent time requires creative thinking: New European concepts in production management. International Journal of Production Management Science, 30, 112-119.

Christopher, M. (2000). The agile supply chain: competing in volatile markets. Industrial Marketing Management, 20, 95-101.

Clark, K.B., \& Fujimoto, T. (1991). Product Development performance: Strategy, organization and management in the world auto industry. Harvard business school press, Cambridge.

Compose, H.M. (2009). Technology strategy and new technology based firm. Journal of Technology Management and Innovation, 4, 133-170.

Fontes, M., \& Coombs, R. (1997). The coincidence of technology and market objectives in internationalization of new technology- based firms. International small Business Journal, 15(4), $22-40$.

Gatignon, H., Xuereb, L. (1997). Strategic orientation of the firm and new product performance. Journal of Marketing Research, 34(1), 77-90.

Gausemeier, J., Dumitrescu, R., Kahl, S., \& Nordsiek, D.(2011). Integrative Development of Product and Production System for Mechatronic Products. Robotics and Computer-Integrated Manufacturing, 27(4), 772-778.

Gausmeier, J.(2002). From Mechatronic to Self - Optimization. Heinz Nixdorf Institute, University of Paderborn, Germany.

Giachetti , R. , Martinez, L., Saenz, O. \& Chen, C.(2003). Analysis of the structural measures of flexibility and agility using a measurement theoretical framework, International journal of production Economics, 86(1), 47-62.

Goldman, S. \& Nagel, R.(1993). Management, technology, and agility: The emergence of new era in manufacturing. International Journal of Technology Management, 8:18-38.

Harrison, A., \& Van Hock, R. (2005). Logistic Management and Strategy. Prentice-Hall.

Hehenberger, P., Poltschak,F., Zeman, K., \& Amrhein, W. (2010). Hierarchical design models in the mechatronic product development process of synchronous machines. Mechatronics, 20(8), 864865.

Hewit, J.R. (1993). Mechatronics an Introduction. Mechatronic New York: Springer-Verlag .

John, S.T., Cannon, C.H, \& Pouder, A. (2001). Change drivers in the new millennium: An agenda for operations strategy research, Journal of Operation Management, 19(2), 143-160.

Khalil, T.M., \& Hazem, E.A. (2005). Management of technology and responsive policies in a new economy. International Journal of Technology Management, 32(1/2), 55-71.

Komoto, H., \& Tomiyama, T. (2010). A system architecting tool for mechatronic systems design. CIRP Annals -Manufacturing Technology, 59(1), 171-174.

Lin, C.H., Chiu, H., \& Chu, P. (2006). Agility index in the supply chain. International Journal of Production Economics, 100, 142-157.

Lo, W.K.(1998). Agility, job satisfaction and organizational excellence, their factorial relationships, ISO-9000 and total quality management - Third proceeding.

Martins, E.C., \& Blanch, F.R. (2003). Building organizational culture that stimulates creativity and innovation, European Journal of Innovation Management, 6(1), 64-74.

McConnel, S. (1996). Rapid Development: Taming Wild Software Schedules. Microsoft Press.

Ramesh, G.,Devadasan, S.(2007). Literature review on the agile manufacturing criteria. Journal of Manufacturing Technology Management, 18(2), 28-42. 
Royce,W. (1970).Managing The Development of large Software systems, Proceedings of IEEE Wescon,1-9.

Seyedhosseini, S.M., \& Keyghobadi A.R. (2010). Characteristics of design and development model for mechatronic, International Academy of Business and Economics, Las Vegas, USA, 17 - 20.

Sharifi, H. \& Zhang, Z. (2001). Agile production in practice: Application of a methodology, International Journal of Operation \& Production Management, 21(5/6), 772-794.

Sharp, J.M., Irani, Z., \& Desai, S.(1999).Working towards agile manufacturing in the UK industry . International Journal of a Production Economics, 62, 155-169.

Souder, W.E , \& Moenart, K.R. (1992). Integrating marketing and R\&D project personnel within Innovation project: An information uncertainly model. Journal of Management Studies, 29(4), 485-512.

Swafford, P. (2006). A framework for assessing value chain agility. International Journal of Operation and Production Management, 24,118-140.

Verein Deutscher Ingenieure (VDI) (1993). The Association of German Engineers, VDI-2221: Systematic Approach to the Development and Design of Technical System and Product, Beuth, Berlin

Verein Deutscher Ingenieure (VDI) (2004). The Association of German Engineers, VDI-2206: Design Methodology for Mechatronical System, Beuth, Berlin.

Verein Deutscher Ingenieure(VDI) (1994).The Association of German Engineers, VDI-2422: Systematical Development of Device Controlled by Microelectronic, Beuth, Berlin.

White, M.A., \& Brunton, G.D. (2007).The management of technology and innovation :A strategic approach. Canada: Thomson south -Western Ltd.

Yang, S., \& Li, T.(2002). Agility evaluation of mass customization product manufacturing, Journal of Material Processing Technology, 129:640-644.

Yin, R.K. (2002). Case study research, design and methods. Sage publication, London.

Yusuf, Y., Sarhai, M., \& Gunasekaran, A. (1999). Agile manufacturing: The drivers, concepts of production. Economic, 62(1/2), 33-43.

Zahra, S.A., \& Bogner, W.C. (2000). Technology strategy and software new ventures, performance: exploring the moderating effect of competitive environment. Journal of Business Venturing, 15(23), 135-173.

Zain , M., Rose, R.C., \& Abdullah, I. (2005). The relationship between information technology acceptance and organizational agility in Malaysia. Information Management, 42(6), 25-31.

Zhang, Z., \& Sharifi, H. (2000). A methodology for achieving agility in manufacturing organization. International Journal of Operation Production Management 20(4), 496-51. 